\title{
Trace Level Gas Sensing Characteristics of Nano-Crystalline Silver Decamolybdate
}

\author{
Sunasira Misra1, Venkataraman Jayaraman², Thiagarajan Gnanasekaran ${ }^{2}$ \\ ${ }^{1}$ Department of Chemistry, C.V. Raman College of Engineering, Bhubaneswar, India; ${ }^{2}$ Chemistry Group, Indira Gandhi Centre for \\ Atomic Research, Kalpakkam, India. \\ Email: misra.sunasir@gmail.com
}

Received October $1^{\text {st }}, 2013$; revised November $11^{\text {th }}, 2013$; accepted November $18^{\text {th }}, 2013$

Copyright (c) 2013 Sunasira Misra et al. This is an open access article distributed under the Creative Commons Attribution License, which permits unrestricted use, distribution, and reproduction in any medium, provided the original work is properly cited.

\begin{abstract}
A soft-chemical method has been developed for the synthesis of nano-crystalline powders of silver decamolybdate. Gas sensing characteristics of this composition both in porous pellet and thin film configurations were investigated. The compound $\mathrm{Ag}_{6} \mathrm{Mo}_{10} \mathrm{O}_{33}$ was found to sense selectively ammonia at $503 \mathrm{~K}$. Above $503 \mathrm{~K}$ it has significant cross sensitivity to petroleum gas (PG). Spin coated thin films exhibited selective sensing towards PG.
\end{abstract}

Keywords: Soft-Chemical Method; Silver Decamolybdate Nano Crystals; Spin Coated Thin Film; Interdigitated Platinum Electrode; Gas Sensor

\section{Introduction}

Ammonia is one of the important raw materials used in many industries. For instance, in fertilizer plants, heavy water plants, etc., where large quantities of ammonia at high pressures are used, leakage of ammonia into air can lead to very undesirable consequences. It is also an explosive gas, which makes an explosive mixture with air. Its lower and upper explosive limit values are between $16 \%$ and $27 \%$ respectively. In addition to being explosive, $\mathrm{TLV}^{1}$ of ammonia is around $25 \mathrm{ppm}$. Hence, its incipient detection is mandatory [1]. Usage of nanoscaled advanced materials and their thick/thin films would make the gas sensors more sensitive, selective, compact and reliable, ensuring the safety aspects and pollution control in industrial environment [1-3].

Silver decamolybdate $\left(\mathrm{Ag}_{6} \mathrm{Mo}_{10} \mathrm{O}_{33}\right)$ is known to be a good material for gas sensing applications [4,5]. In thick film form, it senses ammonia down to $2 \mathrm{ppm}$ by volume in air [6]. Nano-crystalline thin film configuration may enhance its gas sensing characteristics further. In this present work, the gas sensing behaviour of both porous pellet and the spin coated nanocrystalline thin films of silver decamolybdate prepared by solution chemistry route were investigated.

\footnotetext{
${ }^{1} \mathrm{TLV}$ is nothing but the maximum concentration of the species to which people can be exposed continuously 8 hours a day without causing any health hazards.
}

\section{Experimental Methodology}

Silver decamolybdate was prepared by mixing appropriate quantities of aqueous solutions of $\mathrm{AgNO}_{3}$ and $\left(\mathrm{NH}_{4}\right)_{6} \mathrm{Mo}_{7} \mathrm{O}_{24} \cdot 4 \mathrm{H}_{2} \mathrm{O}$ with ammonia solution. The resulting precipitate was heated to $573 \mathrm{~K}$ for $5 \mathrm{~h}$ [7-10]. The resulting nano-crystalline $\mathrm{Ag}_{6} \mathrm{Mo}_{10} \mathrm{O}_{33}$ was made in the form of porous pellets and its gas sensing characteristics were evaluated as mentioned in the previous studies [8]. The test gases used for this study were $100 \mathrm{ppm}$ of $\mathrm{NH}_{3}$, $\mathrm{H}_{2}, \mathrm{NO}_{\mathrm{x}}$ and petroleum gas (PG) by volume. The sensitivity for a given concentration of analyte gas was calculated as follows:

$$
\text { \%Sensitivity }=\left[\left(R_{a}-R_{g}\right) / R_{a}\right] \times 100
$$

where $R_{a}=$ resistance of the pellet in air and $R_{g}=$ resistance of the pellet in air containing the analyte gas.

A Photo Resist Spinner (M/s Ducom, India) was used to spin coat the ammoniacal solutions of $\mathrm{AgNO}_{3}$ and $\left(\mathrm{NH}_{4}\right)_{6} \mathrm{Mo}_{7} \mathrm{O}_{24} \cdot 4 \mathrm{H}_{2} \mathrm{O}$ over polycrystalline alumina substrate of $0.5 \mathrm{~mm}$ thickness at a rate of 1000 revolutions per minute followed by drying it in an oven. This process was repeated several times and then the films were slowly heated at a rate of $1 \mathrm{~K} / \mathrm{min}$ to 773 for half an hour to get $\mathrm{Ag}_{6} \mathrm{Mo}_{10} \mathrm{O}_{33}$ phase [7,9]. Prior to the fabrication of this thin film, a serpentine shaped platinum heater pattern was screen printed on the rear side of the substrate for 
heating the sensor film. The resistance of the Pt-heater was calibrated for various temperatures. Gold contact pads with interdigitated platinum electrodes were screen printed on the front side of substrate for measuring the electrical signal of the thin film. Gas sensing characteristics of nano-crystalline thin film of $\mathrm{Ag}_{6} \mathrm{Mo}_{10} \mathrm{O}_{33}$ mounted in a sensor chamber made of quartz were investigated at various temperatures by injecting $100 \mathrm{vppm}$ of $\mathrm{NH}_{3}, \mathrm{H}_{2}$ and petroleum gas (PG) each. Acquisition of data was carried out as mentioned in the earlier publications $[4,6,8]$.

\section{Results and Discussion}

\subsection{Gas Sensing Characteristics of Porous Pellet Sample}

Both the nano-cyrstalline powder and thin film samples of $\mathrm{Ag}_{6} \mathrm{Mo}_{10} \mathrm{O}_{33}$ were characterized by a variety of physicochemical techniques and the results were presented elsewhere [7-9]. Gas sensing characteristics of the porous pellets comprising nano-crystalline $\mathrm{Ag}_{6} \mathrm{Mo}_{10} \mathrm{O}_{33}$ powders were investigated at various operating temperatures towards four different analyte species.

Figure 1 reveals a sensitivity of $\sim 45 \%$ to $100 \mathrm{vppm}$ ammonia at $503 \mathrm{~K}$. At this temperature it is found that this film is selective to ammonia while the sensitivities to PG, $\mathrm{H}_{2}$ and $\mathrm{NO}_{\mathrm{x}}$ are less than $10 \%$. But, above this temperature this compound shows significant cross sensitivity to PG and sensitivity value reaches about $75 \%$ in the temperature range 570 to $625 \mathrm{~K}$. And it shows lower sensitivities towards $\mathrm{H}_{2}$ and $\mathrm{NO}_{\mathrm{x}}$ above $503 \mathrm{~K}$. The sensing behaviour of this compound prepared by solid-state route is reported by Sunu et al. [5] where it senses ammonia (500 vppm) selectively with a higher sensitivity of $\sim 80 \%$ and lower sensitivity ( $25 \%$ ) towards $500 \mathrm{vppm}$

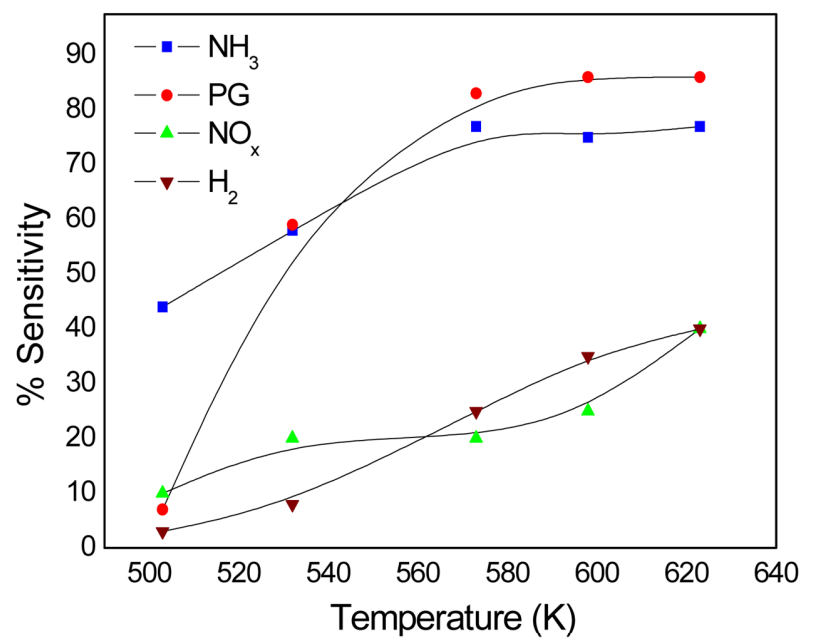

Figure 1. Typical sensitivity values of nano-crystalline $\mathrm{Ag}^{6} \mathrm{Mo}^{10} \mathrm{O}^{33}$ porous pellet towards $100 \mathrm{vppm}$ of four different analytes. of PG and $\mathrm{H}_{2}$ between the temperatures 573 to $673 \mathrm{~K}$. This difference may be attributed to the presence of modified surface states when the compound is prepared by soft-chemical method.

\subsection{Gas Sensing Characteristics of Thin Films}

The gas sensing characteristics of the spin coated $\mathrm{Ag}_{6} \mathrm{Mo}_{10} \mathrm{O}_{33}$ thin film over polycrystalline alumina substrate with interdigitated platinum electrode were investigated towards trace (ppm) level of different toxic and flammable gas analytes at various temperatures. Figure 2 shows the typical response pattern of this film towards various analytes at $573 \mathrm{~K}$. The signal is stable and reproducible with sensitivity of $13 \%$ towards $100 \mathrm{vppm}$ ammonia and 32\% towards $100 \mathrm{vppm}$ petroleum gas at $573 \mathrm{~K}$. The response time of the sensor at this temperature towards ammonia is around $10 \mathrm{~min}$ and the retrace time is $\sim 40 \mathrm{~min}$ whereas for petroleum gas the corresponding values are around 8 and 25 min respectively. It showed negligible sensitivity towards $100 \mathrm{vppm}$ of hydrogen gas.

The mechanism for this ammonia sensing action for bulk $\mathrm{Ag}_{6} \mathrm{Mo}_{10} \mathrm{O}_{33}$ had been investigated and reported by Sunu et al. [5]. Similar mechanism for petroleum gas sensing can be proposed. On reaction with petroleum gas, molybdenum carbide could form along with silver and both products have good electrical conductivity. At this optimised temperature this causes abrupt drop in resistivity value of the material from its stable baseline. However, more experiments are required to support the mechanism proposed. Once the reducing analyte gas is consumed the original baseline is retraced in presence of fresh air (oxygen) reforming the sensor base material $\left(\mathrm{Ag}_{6} \mathrm{Mo}_{10} \mathrm{O}_{33}\right)$. The chemical equations for this mecha-

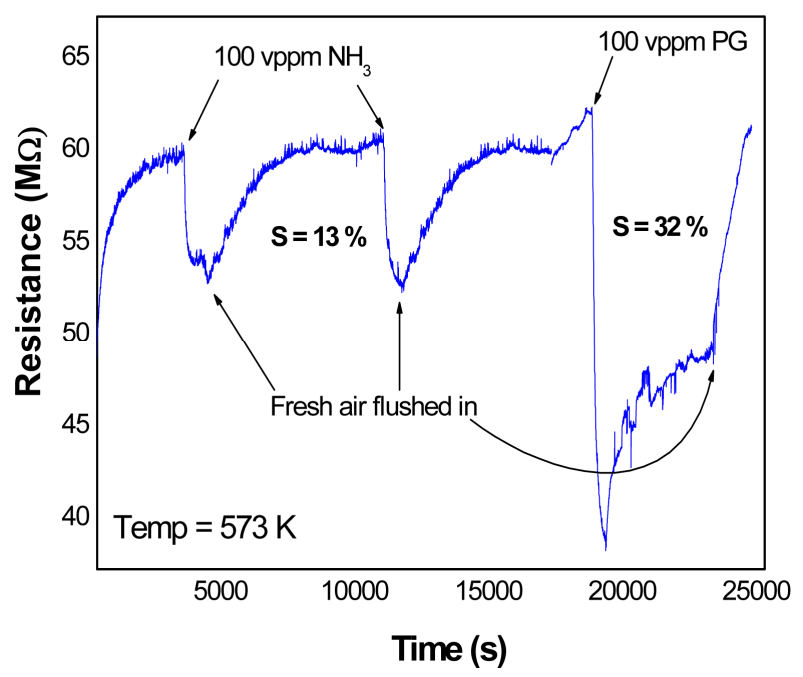

Figure 2. Typical response of nano-crystalline $\operatorname{Ag}_{6} \mathrm{Mo}_{10} \mathrm{O}_{33}$ thin film with Pt-IDE towards 100 vppm of analyte gas at $573 \mathrm{~K}$. 
nism in presence of PG are proposed below.

$$
\begin{aligned}
\mathrm{Ag}_{6} \mathrm{Mo}_{10} \mathrm{O}_{33} \underset{[\text { Air }]}{\stackrel{\mathrm{PG}}{\rightleftarrows}} & 6 \mathrm{Ag}+5 \mathrm{Mo}_{2} \mathrm{C}+11 \mathrm{CO}_{2} \\
+ & 11 \mathrm{H}_{2} \mathrm{O}+12 \mathrm{NH}_{3} \\
\mathrm{Ag}_{6} \mathrm{Mo}_{10} \mathrm{O}_{33} \underset{[\text { Air }]}{\rightleftarrows} & 6 \mathrm{Ag}+2 \gamma-\mathrm{Mo}_{2} \mathrm{~N}+2 \mathrm{MoO}_{2} \\
+ & \mathrm{Mo}_{4} \mathrm{O}_{11}+18 \mathrm{H}_{2} \mathrm{O}+5 \mathrm{~N}_{2}
\end{aligned}
$$

At $673 \mathrm{~K}$ the sensitivity of the film towards $100 \mathrm{vppm}$ ammonia remained unaltered whereas towards $100 \mathrm{vppm}$ petroleum gas the sensitivity decreased to $15 \%$, which is almost equivalent to that of ammonia (Figure 3). The response and recovery of the film towards analytes are also relatively fast at this temperature viz. 1.5 and $7 \mathrm{~min}$ for ammonia and for PG these values are 5 and $4 \mathrm{~min}$ respectively (Table 1). The results also showed almost no sensitivity towards hydrogen. Typical sensitivity values of $\mathrm{Ag}_{6} \mathrm{Mo}_{10} \mathrm{O}_{33}$ thin film towards $100 \mathrm{vppm}$ of different gas analytes at temperatures 573, 598 and $673 \mathrm{~K}$ are clearly depicted in Figure 3. At $573 \mathrm{~K}$, it showed $13 \%$ and $32 \%$ sensitivities towards $100 \mathrm{vppm}$ of $\mathrm{NH}_{3}$ and PG respectively with negligible sensitivity to hydrogen. On comparing this thin film study with its bulk, it is in-

Table 1. Response and recovery time for $\operatorname{Ag}_{6} \mathrm{Mo}_{10} \mathrm{O}_{33}$ thin film towards 100 vppm of $\mathrm{NH}_{3}$ and PG each at 573 and 673 K.

\begin{tabular}{ccccc}
\hline \multirow{2}{*}{$\begin{array}{c}\text { Time in } \\
\text { min }\end{array}$} & $\begin{array}{c}c \\
\mathrm{NH}_{3}\end{array}$ & $\mathrm{PG}$ & \multicolumn{2}{c}{ At 673 K } \\
\cline { 2 - 5 } & $(100 \mathrm{vppm})$ & $\mathrm{NH}_{3}$ & $\mathrm{PG}$ \\
Response & 10 & 8 & 1.5 & 5 \\
Recovery & 40 & 25 & 7 & 4 \\
\hline
\end{tabular}

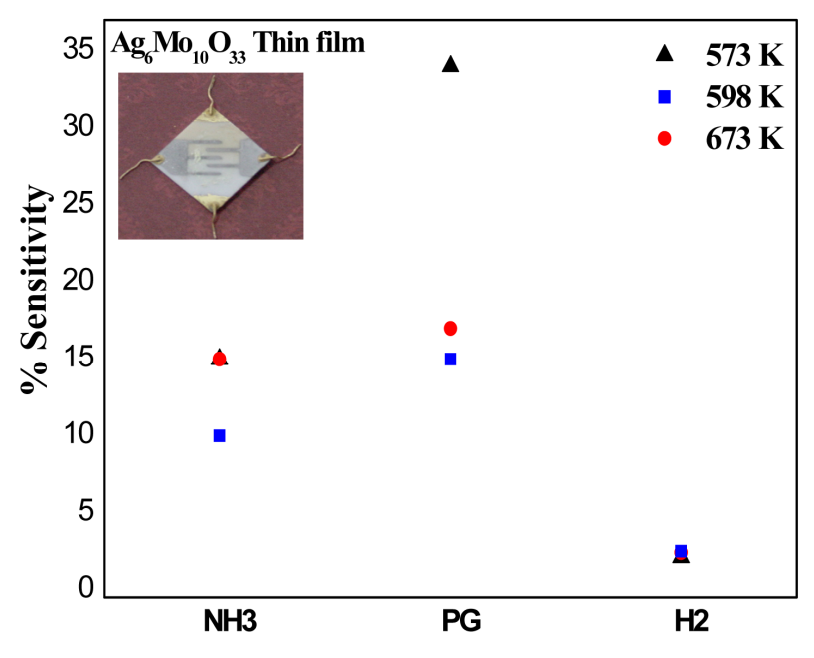

Analytes of $100 \mathrm{vppm}$ concentration

Figure 3. Typical sensitivity values of nano-crystalline $\mathrm{Ag}_{6} \mathrm{Mo}_{10} \mathrm{O}_{33}$ thin film towards $100 \mathrm{vppm}$ of different gas analytes at $T=573,598$ and $673 \mathrm{~K}$. ferred that at an optimum temperature of $573 \mathrm{~K}$, pellet has also similar trend, but higher sensitivity of $77 \%$ towards $100 \mathrm{vppm}$ ammonia and 83\% towards $100 \mathrm{vppm}$ petroleum gas.

\section{Conclusion}

Using the present soft-chemical method we could successfully synthesize nano-crystalline powders as well as thin films of $\mathrm{Ag}_{6} \mathrm{Mo}_{10} \mathrm{O}_{33}$ on polycrystalline alumina substrate. The nano-crystalline $\mathrm{Ag}_{6} \mathrm{Mo}_{10} \mathrm{O}_{33}$ is found to sense selectively ammonia at $503 \mathrm{~K}$. But, above $503 \mathrm{~K}$ this compound has high cross sensitivity towards petroleum gas (PG). $\mathrm{Ag}_{6} \mathrm{Mo}_{10} \mathrm{O}_{33}$ thin film sensor with IDE showed $13 \%$ sensitivity towards $100 \mathrm{vppm}$ ammonia, $32 \%$ towards $100 \mathrm{vppm}$ petroleum gas and negligible sensitivity towards $100 \mathrm{vppm}$ hydrogen at an optimum temperature of $573 \mathrm{~K}$. Thus, for ammonia and petroleum gas sensing applications, fabrication of compact device with $\mathrm{Ag}_{6} \mathrm{Mo}_{10} \mathrm{O}_{33}$ thin film on substrate patterned with interdigitated Pt-electrodes can be recommended where there is no interference from each other between the two analytes. The exact sensing mechanism for PG is not known.

\section{REFERENCES}

[1] N. Yamazoe and N. Miura, "Chemical Sensor Technology,” Vol. 4, Kodansha-Elsevier, New York, 1998.

[2] W. Gopel and K. D. Schierbaum, "Definitions and Typical Examples,” In: W. Gopel, et al., Eds., Sensors, a Comprehensive Survey, Weinheim, 1991, pp. 1-28.

[3] J. Gerblinger, K. H. Hardtl, H. Meixner and R. Aigner, "High-Temperature Microsensors," In: W. Gopel, Ed., Sensors, A Comprehensive Survey, Weinheim, 1995, 181219.

[4] S. S. Sunu, E. Prabhu, V. Jayaraman, K. I. Gnanasekar, T. K. Seshagiri and T. Gnanasekaran, "Electrical Conductivity and Gas Sensing Properties of $\mathrm{MoO}_{3}$," Sensors and Actuators B: Chemical, Vol. 101, 2004, pp. 161-174. http://dx.doi.org/10.1016/j.snb.2004.02.048

[5] S. S. Sunu, V. Jayaraman, E. Prabhu, K. I. Gnanasekar and T. Gnanasekaran, " $\mathrm{Ag}_{6} \mathrm{Mo}_{10} \mathrm{O}_{33}-\mathrm{A}$ New Silver ion Conducting Ammonia Sensor Material,” Ionics, Vol. 10, No. 3-4, 2004, pp. 244-253. http://dx.doi.org/10.1007/BF02382824

[6] E. Prabhu, S. Muthuraja, K. I. Gnanasekar, V. Jayaraman, S. Sivabalan and T. Gnanasekaran, "Ammonia Sensing Properties of Thick and Thin Films of $\mathrm{Ag}_{6} \mathrm{Mo}_{10} \mathrm{O}_{33}$ and $\mathrm{Cr}_{1 \cdot 8} \mathrm{Ti}_{0 \cdot 2} \mathrm{O}_{3}+$," Surface Engineering, Vol. 24, No. 3, 2008, pp. 170-175. http://dx.doi.org/10.1179/174329408X298229

[7] S. Misra, "Investigations on Electrical and Gas Sensing Characteristics of Pure and Substituted $\mathrm{SrMO}_{3}(\mathrm{M}=\mathrm{Ti}$, Sn and Zr) Perovskites and Silver Molybdates,” Ph.D. Thesis in Chemistry, University of Madras, Chennai, 2010, 175-181. 
[8] S. Misra, V. Jayaraman and T. Gnanasekaran, "Electrical Conductivity and Ammonia Sensing Characteristics of Nanocrystalline Silver Molybdates Synthesized by Solution Chemistry Route,” IEEE Explore Digital LibraryInternational Conference Proceedings of NSTSI, Bhubaneswar, 8-10 December 2011, pp. 1-6. http://dx.doi.org/10.1109/NSTSI.2011.6111791

[9] S. Misra, S. Sahoo, V. Jayaraman, A. K. Arora and T. Gnanasekaran, "Effect of Annealing on Microstructure and Phase Evolution of $\mathrm{Ag}_{6} \mathrm{Mo}_{10033}$ Nanorods Synthesised by Novel Soft Chemical Method,” Interna- tional Journal of Nanotechnology, Vol. 7, No. 9-12, 2010, pp. 870-882. http://dx.doi.org/10.1504/IJNT.2010.034695

[10] A. K. Arora, R. Nithya, S. Misra and T. Yagi, "Behavior of Silver Molybdate at High-Pressure," Journal of Solid State Chemistry, Vol. 196, 2012, pp. 391-397. http://dx.doi.org/10.1016/j.jssc.2012.07.003 